\title{
Modification of biomarkers in pyrogenic organic matter during the initial phase of charcoal biodegradation in soils
}

\author{
H. Knicker*¹ ${ }^{1}$ A. Hilscher ${ }^{1,2}$, J.M de la Rosa ${ }^{1}$, J.A. González-Pérez ${ }^{1}$, F.J. González-Vila ${ }^{1}$
}

${ }^{1}$ IRNAS-CSIC, Avenida Reina Mercedes 10, 41080 Seville, (Spain)

${ }^{2}$ Lehrstuhl für Bodenkunde, TU-München-Weihenstephan, Emil-Ramann-Straße 2, 85354

Freising (Germany)

Keywords: lipids, levoglucosan, biomarker, plant chars, rye grass, Scots pine, Black Carbon degradation

\section{Abstract}

The biochemical stability of typical biomarkers of different plant chars during biotic degradation was examined using pyrogenic organic matter (PyOM) derived from rye grass (Lolium perenne; Gr) and pine wood (Pinus sylvestris; $\mathrm{P}$ ) heated at $350^{\circ} \mathrm{C}$ for one $(1 \mathrm{M})$ and four minutes $(4 \mathrm{M})$ under oxic conditions. The composition of the $n$-alkanes and $n$-fatty acids (FA) as well as the contents of the molecular markers levoglucosan and vanillin were determined and related to charring intensity and stability to microbial reworking. Our results confirmed that charring of plant residues results in typical thermal breakdown processes of $n$ alkanes and FA. Prolonged charring reduced the average chain length of $n$-alkanes by up to four carbons and shifted the characteristic odd/even predominance of fresh plants towards a balanced odd/even distribution. The unsaturated FA fraction was more prone to heat degradation than the saturated counterparts. Especially, linoleic acid $\left(\mathrm{C}_{18: 2}\right)$ and $\alpha$-linolenic acid $\left(\mathrm{C}_{18: 3}\right)$ were depleted in the severely charred grass, whereas oleic acid $\left(\mathrm{C}_{18: 1}\right)$ was still present. Levoglucosan was detectable in all PyOMs, but the pine charred for one minute (P1M) contained the largest amount. Progressive heating resulted in a strong depletion of levoglucan for both plant materials. The pine char showed a relative accumulation of vanillin, supporting that some lignin-derived structures can survive charring. Microbial decomposition of the chars within a soil matrix for seven weeks demonstrates that during initial PyOM biodegradation, $n$-alkanes and FA series are rapidly modified by microbial reworking and biosynthesis. After the incubation, the pine chars were enriched in $n$-alkane octadecane $\left(\mathrm{C}_{18}\right)$ and homologues in the range from $\mathrm{C}_{22}$ to $\mathrm{C}_{26}$. The $n$-alkanes and FA of the grass chars were 
more severely affected than those of the pine chars. Levoglucosan was efficiently decomposed, indicating that care has to be taken if these compounds are used as char tracer in soils, since their instability against biodegradation may hamper the identification of charcoal residues.

\section{Introduction}

Wildfires convert large amounts of biomass carbon into $\mathrm{CO}_{2}$ and charred residues, which after their incorporation into the soil may contribute to carbon sequestration by increasing the slow organic matter pool. In contrast to older models, assuming that charcoal represents a highly condensed polyaromatic network, a newer concept describes this material as a heterogeneous mixture of partially degraded and heat-altered biomacromolecules, the alteration degree of which depends upon the chemical composition of the source material as well as upon the charring conditions (Knicker et al., 2008). Beside of charred carbohydrates, peptides and lignin residues, thermally-altered lipids represent a further important fraction of pyrogenic organic matter (PyOM) (González-Vila et al., 2001).

Compared to other plant components, lipids are less abundant, but occur with a typical pattern. Since in certain environment, some of them are more recalcitrant than other biomolecules (Fridland, 1982; Stevenson, 1994), they are often used as biomarkers. Within the lipid fraction, $n$-alkanes and aromatic hydrocarbons are less efficiently biodegraded than medium chain fatty acids and alcohols (Nguyen Tu et al., 2001; Wiesenberg et al., 2004). However, using lipids as biomarkers, one has to be aware that in spite of their recalcitrance, after entering the soil, their composition can be altered either by microbial degradation processes or by re-synthesis of microbial biomass. Further changes can occur due to lipids derived from decaying root residues or root related exudations (Breger, 1966; Dinel et al., 1990).

After vegetation fires, the incorporation of PyOM into the soil is expected to have some essential impact on the pattern of the lipid fraction of soil organic matter (SOM). GonzálezPérez et al. (2008) found that wildfires exert shifts in the distribution of $n$-alkane and fatty acids of SOM. Wiesenberg et al. (2009) reported that charring grass at $500^{\circ} \mathrm{C}$ resulted in a pronounced shortening of $n$-alkane chain length maximising at $\mathrm{C}_{18}$ and to an even numbered chain length distribution. Almendros et al., (1988) and Tinoco et al. (2006) suggested that such thermally altered lipids can be incorporated as constituents of the soil lipid fraction of fire-affected Mediterranean soils under pine. Wiesenberg et al. (2009) pointed out that the composition of aliphatic and aromatic hydrocarbons of fire-effected recent and fossil soils 
offers specific fingerprint indicators for diagnosis of vegetation burning and burning conditions. Eckmeier and Wiesenberg (2009) analysed lipids from buried ancient topsoils, containing charred organic matter, and found a particular pattern of short-chain and even carbon numbered $\mathrm{n}$-alkanes with a maximum at $\mathrm{C}_{16}$ or $\mathrm{C}_{18}$ associated by the authors to the occurrence of charred biomass.

A further important biomarker group comprises lignin derivatives. Lignin is the most abundant polymeric aromatic organic substance in plants and in wood its contribution can account for 20 to $40 \%$ of the plant biomass (Fengel and Wegener, 1984). Sharma et al. (2004) and Knicker et al. (2008) demonstrated that the lignin backbone can survive charring of plants. To which extent the input of such charred residues will affect the composition of the lignin pool of fire-affected soils, however, is not well understood, yet.

Levoglucosan (1,6-anhydro- $\beta$-1D-glucopyranose) is a major product derived from the thermal decomposition of cellulose (Lakshman and Hoelsche, 1970; Simoneit et al., 1999). This compound has been proposed as a typical marker indicating combustion of vegetation and can be identified both in soils (Kuo et al., 2008; Otto et al., 2006) and sediments (Elias et al., 2001). Elias et al. (2001) reported a correlation between levoglucosan and the counted charcoal content in a sediment core from a lake in Carajas (Southeastern Amazonia). Kuo et al. (2008) examined systematically the levoglucan levels of charcoal produced from tree plant materials under controlled combustion conditions ranging from 150 to $1050^{\circ} \mathrm{C}$, and lasting from 0.5 to $5 \mathrm{~h}$. The authors reported large differences of levoglucan yields in chars across plant species and charring temperatures. They concluded that levoglucan may not be as appropriate as marker for the quantitative characterisation of char in the environment as formerly thought. However, alterations of LG are also likely to occur after their incorporation into the SOM pool as a result of microbial reworking.

In general, the identification and application of specific biomarker for char detection in soils and sediments is largely based on studies using freshly produced charred plant materials (e.g. (Wiesenberg et al., 2009)) and the assumption that charred residues are biochemically highly stable and thus their biomarkers could be preserved on a long-term scale. In fact, recent studies demonstrated that under laboratory conditions, but also in some field studies, char shows mean turnover rates on a decade scale (Bird et al., 1999; Hamer et al., 2004; Hilscher et al., 2009). Degradation studies of fire-affected soils confirmed such short mean turnover rates and demonstrated that charcoal input into soil only slightly increased the stability of its slow carbon pool (Knicker et al., 2012). To which extend the biodegradability of char may 
affect the stability of its biomarkers, however, is not well established, yet. Just as well, studies about the fate of those constituents during humification are scarce.

Bearing in mind the above-mentioned considerations, one task of the present study was to analyse the effects of burning on the lipid fraction and other potential biomarkers of plant biomass which are co-extracted with lipids. Subsequently, we elucidated the stability of those components during decomposition and humification of charred residues. With this, we intended to find typical molecular patterns attributable to charred biomass and to reveal how they are altered by microbial reworking during the early post-fire phase. The identification of such chances represents an important premise for an improved evaluation of the reliability of the biomarker approach as a tool for the investigation of the role of char contribution to quality and function of SOM pools. Therefore, we used PyOM, derived from charring rye grass and pine wood at $350^{\circ} \mathrm{C}$ under oxic conditions, which was previously well characterized for the biochemical recalcitrance by laboratory respiration experiments and solid-state nuclear magnetic resonance spectroscopy (Hilscher et al., 2009). The goal of the present study was to supplement those examinations by a detailed analysis of the stability of selected biomarkers during the microbial degradation of the plant chars. The analysis was performed applying gas chromatography - mass spectrometry (GC-MS) and included $n$-alkanes and $n$-fatty acids, levoglucan and vanillin as typical thermal decomposition product of lignin.

\section{Material and Methods}

\subsection{Sample material}

The samples derived from rye grass (Lolium perenne) and pine wood (Pinus sylvestris). Details on the production and chemical characteristics of the fresh plant material and the pyrogenic organic matter (PyOM) are published elsewhere (Hilscher et al., 2009). In short, approximately $5 \mathrm{~g}$ of dried rye grass $(\mathrm{Gr})$, cut into small pieces (5 to $10 \mathrm{~mm}$ ) and pine wood (P) ground to a particle size of $1 \mathrm{~mm}$ were put in a $1 \mathrm{~mm}$ layer on a ceramic tray which was preheated at a temperature of $350^{\circ} \mathrm{C}$. This tray was put into a preheated muffle furnace to allow charring at $350^{\circ} \mathrm{C}$ under oxic conditions to ensure that plant material is immediately exposed to the target charring temperature. This temperature was used because it produces chars that are comparable to those remaining after natural wildfires (Almendros et al., 1990). At higher temperatures, most unprotected organic matter is expected to be volatilised under the natural oxic conditions of wildfires. Two oxidation times of $1 \min (1 \mathrm{M})$ and $4 \min (4 \mathrm{M})$ were applied to obtain materials with different charring degree. 
The degradation of the PyOM was performed using a Respicond Apparatus IV (Nordgren Innovations, Sweden) as previously described (Hilscher et al., 2009). Therefore, the PyOM was mixed in a ratio $1 / 10(\mathrm{w} / \mathrm{w})$ with material of a fire-unaffected $\mathrm{Bw}$ horizon of a Cambisol (IUSS Working Group WRB, 2006) under spruce located close to Leuk, Canton Valais, Switzerland, (GPS $46.33678^{\circ} \mathrm{N}, 7.64394^{\circ} \mathrm{E}$ ) (WRB, 2006). This soil was used due to its low organic carbon content. Aliquots of $30 \mathrm{~g}$ of each mixture were placed in 250-ml incubation vessels. For the degradation study, 5 and 2 replicates were prepared of the rye grass char and for the pine wood char, respectively. All samples were inoculated with $1 \mathrm{ml}$ of a microbial suspension extracted from a gardening soil with deionised water and subsequent filtering (5 $\mu \mathrm{m}$ pore size). The water content of the sample mixtures was adjusted to $c a$. $60 \%$ of the maximum water holding capacity and the samples were incubated for seven weeks at $30^{\circ} \mathrm{C}$ under aerobic conditions. After the incubation, a representative composite sample was prepared by mixing the sub-samples.

\subsection{Biomarker extraction}

Aliquots from ground and dried incubated samples (10 g), as well as of the fresh and charred plant material ( $1 \mathrm{~g})$ were Soxhlet-extracted with a dichloromethane-methanol (3:1 v:v) mixture for 48 h (González-Vila et al., 2003). The total lipid extracts were filtrated and subsequently dried with sodium sulphate. Their yields were determined gravimetrically and related to the total carbon content of the original samples. Prior to analysis by gas chromatography-mass spectrometry (GC-MS; Hewlett-Packard GCD), the total extracts were derivatised with $2 \mathrm{M}$ trimethylsilyldiazomethane for the methylation of polar compounds. In addition, silylation of the extracts was performed, using $\mathrm{N}, \mathrm{O}$-bis(trimethylsilyl)trifluoroacetamide. Thus, the polar compounds were identified as their methyl or silyl esters.

The GC-MS analysis was performed with a SE-52 fused silica capillary column $(30 \mathrm{~m} \times 0.32$ $\mathrm{mm}$ i.d., film thickness $0.25 \mu \mathrm{m}$ ) applying an oven temperature program increasing from 40 to $100{ }^{\circ} \mathrm{C}$ at $30^{\circ} \mathrm{C} \mathrm{min}^{-1}$ and then until $300{ }^{\circ} \mathrm{C}$ at $6{ }^{\circ} \mathrm{C} \min ^{-1}$. Helium was used as carrier gas at a flow rate of $1.5 \mathrm{ml} \mathrm{min}^{-1}$. Mass spectra were measured at $70 \mathrm{eV}$ ionising energy. Individual compounds were identified by low resolution mass spectrometry and by comparison with published mass spectra libraries (NIST and Wiley) supplied with the instrument software. Traces corresponding to selected homologous series of biomarkers families were obtained by single ion monitoring (SIM) of ions characteristic, such as ion at $m / e 85$ for $n$-alkanes and ion at $m / e 74$ for FAMES (fatty acid methyl esters). The analysis was performed in triplicate. The compound abundance was assessed by determination of the relative intensities of the traces 
via the software of the Data Review Chemstation. Standard deviations of less than 5\% were calculated, supporting a good reproducibility of our results. In order to account for the background concentration of the soil matrix in the incubated soil/PyOM mixture, the abundance of the respective compound detected in the extract of the pure soil matrix was subtracted from that identified in the sample. However, the yield of the extract from the pure soil matrix was only $0.16 \pm 0.02 \mathrm{mg} \mathrm{g}^{-1}$ dry soil.

\section{Results and discussion}

The amount of extracted organic matter of the initial biomass were comparable and accounted to $67 \mathrm{mg} \mathrm{g}^{-1}$ dry grass and $62 \mathrm{mg} \mathrm{g}^{-1}$ dry pine, which are typical amounts for these plant materials (Wiesenberg et al., 2009). During the first minute of charring, the grass and the pine samples lost $44 \%$ and $16 \%$ of its carbon, respectively. After 4 minutes of heat treatment these numbers increased to 53 and $51 \%$ (Hilscher et al., 2009). This C-loss also affected the amount of extractable organic matter of those samples resulting in its consecutively decrease with charring time, which can be explained by heat-induced cracking and volatilisation of the products (Simoneit and Elias, 2001; Yokelson et al., 1997) (Table 1). The extractable fraction of grass-derived PyOM was up to 3.6 times higher than that of pine. The lowest yields $(3 \mathrm{mg}$ $\left.\mathrm{g}^{-1}\right)$ were determined for the more severely charred pine sample (P4M).

\section{2 -Alkane pattern of the fresh and incubated PyOM}

The total abundance of $n$-alkanes in the fresh rye grass straw (GrOM) lies with $55 \mu \mathrm{gg}^{-1}$ in the range reported previously (Wiesenberg et al., 2009). This sample showed a predominance of long chain odd numbered $n$-alkanes in the range of $\mathrm{C}_{25}$ to $\mathrm{C}_{33}$ and $\mathrm{C}_{29}$ as the dominant homologue within the aliphatic hydrocarbons (Fig 1). This pattern is well established for higher plants (Eglinton et al., 1962; Eglinton and Hamilton, 1967), and comparable to that described in detail for grasses by Maffei (1996). As expected for a woody sample without any contributions of epicuticular waxes, the fresh pine wood P0M) showed minor contributions of low and mid chain $n$-alkanes which also occurred without any regular distribution (Fig. 1). Charring the grass residues resulted in an increase of the abundance of $n$-alkanes by factors of $3.6(\mathrm{Gr} 1 \mathrm{M})$ and $2.6(\mathrm{Gr} 4 \mathrm{M})$ relative to the unheated material (Table 1). This is partly attributed to a selective enrichment caused by their higher thermal stability if compared to other plant components, but can also result from breakdown processes of other higher molecular weight lipids, e.g. decarboxylation of fatty acids (FA). The average chain length (ACL) decreased with prolonged charring time for the grass derived PyOM (Table 1). Degradation is further indicated by the carbon preference index $(\mathrm{CPI})$, relating the abundance 
of even and odd numbered $n$-alkanes, which decreases from 3.7 and 2.3 in the extract of the fresh grass and plant to around 1 in that of the charred samples. Due to the preferential biological production of add numbered $n$-alkanes, fresh plant residues show a CPI $>1$. Thus, the observed alteration of CPI and ACL support that charring resulted in a shift of the natural predominance of long chain odd numbered $n$-alkanes towards a larger contribution of mid chain even numbered $n$-alkanes $\left(C_{19}\right.$ to $\left.C_{25}\right)$. The latter is caused by thermally induced breakdown processes of long chain $n$-alkanes and is also detected in fire-affected soils (GonzálezPérez et al., 2008). The thermal degradation of high molecular weight constituents is confirmed by the fact that the decrease of CPI was pronounced in particular for the long chain $n$-alkanes $\left(\mathrm{C}_{25}\right.$ to $\left.\mathrm{C}_{31}\right)\left(\mathrm{CPI}_{\text {long }}\right)$ and that the ratio $\mathrm{R}_{\mathrm{s} / 1}$ between short chain $(\mathrm{C} 15$ to $\mathrm{C} 24)$ and long chain (C25 to C33) n-alkanes increased from 0.5 to 4.1 (Table 1 ). The dominance of even homologues caused by thermal degradation is also reported by Wiesenberg et al. (2009) for grass and for soils (Almendros et al., 1988; Eckmeier and Wiesenberg, 2009; GonzálezPérez et al., 2008; Tinoco et al., 2006).

Relative to the starting material lower amounts of fatty acids were isolated from the pine chars than from the grass chars. This is best explained by the fact that relative to the grass material, the fresh pine residues contained a lower fraction of fatty acids which than was available for thermally induced decarboxylation. Concomitantly, the pine chars showed a lower abundance of $n$-alkanes than the grass chars. The odd to even predominance (CPI) for $n$-alkanes was only slightly reduced by charring and no major alteration of the ACL was revealed (Table 1). The grass and pine char obtained after $4 \mathrm{~min}$ of charring indicated a similar $n$-alkane pattern (Table 1 and Fig. 1) with $\mathrm{C}_{18}$ (rye grass) and $\mathrm{C}_{20}$ (pine) as dominant homologues. Compared to the chars obtained after one minute, however, the total yield of $n$ alkanes decreases for both plant chars and $\mathrm{R}_{\mathrm{s} / 1}$ increased slightly indicating a stronger degradation of long chains. This is in contrast to previous studies showing no major alteration of the yields by increasing the charring time up to a factor of twelve at charring temperatures between 300 and $400^{\circ} \mathrm{C}$ (Eckmeier and Wiesenberg, 2009). This difference is best explained by different charring conditions. Whereas, the latter were performed under $\mathrm{O}_{2}$-deficiency, the presence of $\mathrm{O}_{2}$ during our charring experiment seems to have provoked a more severely degradation of $n$-alkanes.

After seven weeks of aerobic incubation of the soil/PyOM mixtures, the cumulative contents of $n$-alkanes of the grass-derived PyOM were reduced to $61 \%$ in the Gr1M incubate $\left(\mathrm{Gr}_{1} \mathrm{M}_{\mathrm{Inc}}\right)$ and to $85 \%$ in that of $\operatorname{Gr} 4 \mathrm{M}\left(\mathrm{Gr}_{\mathrm{Inc}}\right)$ (Table 2). The higher recovery for the latter may be explained by physical entrapment. The ACL of the $n$-alkanes in $\mathrm{Gr}_{1} \mathrm{M}_{\text {Inc }}$ is two carbon 
homologues shorter than that of the fresh grass PyOM, indicating degradation of long chain homologues $\left(>\mathrm{C}_{26}\right.$ ) and/or biosynthesis by microorganisms (Fig. 1). This conclusion is supported by an increasing $\mathrm{R}_{\mathrm{s} / 1}$ ratio (Table 2). The CPI index for the incubated grass-derived PyOM is in the same range (between 0.9 and 1.1) than that for fresh PyOM (Table 2).

Ambles (1994) performed a biodegradation study of pure eicosane $\left(\mathrm{C}_{20}\right)$ added to material of a Rendzina and reported a fast decline of $71 \%$ of this compound after one week and of $89 \%$ after eight weeks. The authors found that only $25 \%$ of the eicosane loss could be explained by mineralisation processes and concluded that the remaining decrease was mainly due to biotransformation processes or transfer into other SOM fractions. In our experiments, the observed decline of the $n$-alkanes fraction during decomposition of PyOM is most tentatively caused by a combination of degradation, biotransformation and transfer in other SOM pools. The incubated pine chars showed a different $n$-alkane distribution trend. In general, the recovery was two to three times higher than in the chars before incubation (Table 2). In particular octadecane $\left(\mathrm{C}_{18}\right)$ and the mid-chain homologues in the range $\mathrm{C}_{22}$ to $\mathrm{C}_{26}$ were formed (Fig.1). Both pine chars experienced comparable alterations, although the abundance of the $n$-alkanes declined by a factor of 2.2 for $\mathrm{P} 4 \mathrm{M}_{\text {Inc }}$. This production of $n$-alkane during the incubation was unexpected. Since we observed a fungus-like exhalation on the char incubates a possible explanation for $n$-alkane formation may be the biosynthesis of mycelial hydrocarbons. Generally, fungal biomass contains $n$-alkanes in the range from $\mathrm{C}_{15}$ to $\mathrm{C}_{36}$ with the predominance of long-chain $\mathrm{C}_{19-30}$ homologues (Jones, 1969; Merdinger and Devine, 1965; Merdinger et al., 1968) which is in agreement with the observed $n$-alkane distribution in the present study and the interpretation of Marseille et al. (Marseille et al., 1999) who explained large concentrations of $\mathrm{C}_{25}$ and $\mathrm{C}_{27} n$-alkanes of decomposed forest litter layers by microbial biosynthesis, most probably of fungi.

Our observations indicate that the microbial degradation of PyOM can either reduce the amount of $n$-alkane as it was evidenced during the decomposition of the grass char, or can increase it as it was deduced for the pine chars. Which pathways will occur, however, seems to depend upon the plant source material and thus the chemical composition of the respective PyOM.

Eckmeier and Wiesenberg (2009) propose short-chain $n$-alkanes $\left(\mathrm{C}_{16-20}\right)$ distribution in ancient soils as molecular marker for prehistoric biomass burning, but our study indicates that this may be valid only if other factors such as microbial activity can be excluded. Otherwise, thermally altered and microbial $n$-alkanes are difficult to distinguish. Studying Australian woodland and grassland soils, specific vegetation with short chain $n$-alkanes and an even to 
odd predominance was suggested to determine the pattern of the $n$-alkanes in the soil (Kuhn et al., 2010). However, such short chain $n$-alkanes were not identified in the plant material used in the present study.

\subsection{Free fatty acid pattern of the fresh and incubated PyOM}

The free FA fraction of the fresh plant materials was mainly composed of saturated, as well as mono-, di- and tri-unsaturated straight-chain homologues (Fig. 2). The total FA abundance of the fresh rye grass was 15.5 times higher than that of the pine wood (Table 1). The FAs palmitic acid $\left(\mathrm{C}_{16: 0}\right)$, linoleic acid $\left(\mathrm{C}_{18: 2}\right)$ and $\alpha$-linolenic acid $\left(\mathrm{C}_{18: 3}\right)$ were highly abundant in fresh grass with $39 \%$ of the total ion current (TIC), constituting $87 \%$ of FA extracted from rye grass (Fig. 2). This observation is in line with previous findings for grasses (Dungait et al., 2010; Jansen et al., 2006; Wiesenberg et al., 2004). The FA distribution of the pine wood was dominated by $\mathrm{C}_{16}$ and $\mathrm{C}_{18: 1}$ chains. These mid-chain compounds are ubiquitous in living biomass (Jaffé et al., 1996). The content of FA was with $639 \mu \mathrm{g} \mathrm{g}^{-1}$ in the range reported in the literature (Willför et al., 2003) for Scots pine sapwood. In contrast to the $n$-alkanes, the FAs of the fresh materials were characterised by a considerable even to odd $\mathrm{C}$ number predominance with a CPI of 24.5 (rye grass) and 40.6 (pine) which is typical for FA.

During the charring process, the amount of FA decreased by a factor of 8.1 and 3.8 for Gr4M and P4M. In general, the unsaturated FAs were more depleted relative to the saturated counterparts (Fig. 2). Prolonging the charring time of the grass strongly decreased the contribution of the latter to the FA fraction from $57 \%$ to $8 \%$ (Table 1). In particular, linoleic acid $\left(\mathrm{C}_{18: 2}\right)$ and $\alpha$-linolenic acid $\left(\mathrm{C}_{18: 3}\right)$ were affected by this decline Fig. 2$)$, whereas oleic acid $\left(\mathrm{C}_{18: 1}\right)$ was reduced but still present. The ratio of $\mathrm{C}_{18: 0}$ to the unsaturated counterparts $\mathrm{C}_{18: 1-3}$ displays a relative enrichment of saturated $\mathrm{FA} \mathrm{C}_{18: 0}$ with prolonged charring time (Table 1). It can be concluded that severely charred plant materials is depleted in unsaturated FA homologues. The increasing ratio $\mathrm{R}_{\mathrm{FA} s / 1}$ of the saturated mid and short-chain $\mathrm{FA}\left(\mathrm{C}_{10-20}\right)$ related to the long chain saturated $\mathrm{FA}\left(\mathrm{C}_{21-28}\right)$ indicates a relative enrichment of mid chain homologues with higher charring intensity which was most likely caused by cracking of carbon bonds (Table 1).

The decrease of the recovery of saturated FA to $72 \%$ for Gr1M and $66 \%$ for Gr4M points to their degradation and transformation to other soil organic matter groups (Table 2). The unsaturated FA followed the same trend (Fig. 2). In contrast, charring pine led to a formation of FA with enrichment factors of 2.7 and 4.6 for the saturated FA (Table 2). The largest increase was found for FA $\mathrm{C}_{16: 0}$ and the $\mathrm{C}_{18}$ homologues (Fig. 2). An enrichment factor of 2.3 
was detected for the $\mathrm{FA} \mathrm{C}_{18: 1}$ of the P1M incubate. This can be taken as a further evidence for microbial activity for example of fungi that grow on the char.

This assumption is supported by the fact that the FA composition of mould fungi is also dominated by saturated and unsaturated FA with 16 and 18 carbon atoms (Cooney and Proby, 1971; Foppen and Gribanov, 1968; Rambo and Bean, 1969). Note that the more severely charred $\mathrm{P}_{4} \mathrm{M}_{\text {Inc }}$ showed a higher FA re-synthesis as compared to $\mathrm{P} 1 \mathrm{M}_{\text {Inc }}$ with enrichment factors of 3.1 and 3.2 for $\mathrm{C}_{16: 0}$ and $\mathrm{C}_{18: 0}$, respectively (Fig. 2). Recent solid-state nuclear magnetic resonance analysis of the biotic degradation of the pine chars demonstrated an enhanced oxidation of aryl structures with charring intensity (Hilscher et al., 2009). This supports the idea of higher microbial activity and thus a higher content of biomass in $\mathrm{P} 4 \mathrm{M}_{\text {Inc }}$. The molecular ratios ACL and CPI of all incubated PyOM are in the same range as of the fresh ones. Only the reduced ratio $\mathrm{R}_{\mathrm{FA} / 1}$ indicates an enrichment of long chain FA $\mathrm{C}_{>20}$. Comparably, González-Pérez et al. (2008) reported a comparable tendency of increasing $\mathrm{R}_{\mathrm{FA}}$ $\mathrm{s} / \mathrm{l}$ after forest fire in soil. The authors describe a trend to reach the initial values of the control soils after approximately five years and attributed this to the input of fresh litter. Because no fresh plant material was added in our experiments, the alterations in our samples strongly supports a neo-formation of FA by in situ biotic processes.

\subsection{Degradation of biomarkers for plant source material and biomass burning}

The lipid extract of the fresh pine wood (POM) contains biomarkers such as resinic acids (abietic acid, dehydroabietic acid, 7-oxodehydroabietic acid, primeric acid; Table 3) which are typical for conifers (Valentin et al., 2010; Willför et al., 2003). In total the resinic acids accounted for $18.6 \%$ of the TIC, whereas dehydroabietic acid is the major resin constituent (70.2\%). Stilbene derivatives are with $12.5 \%$ of the TIC the second main component of the pine wood extract. The presence of vanillin, which is the primary aromatic alcohol monomer of gymnosperm lignin is a further typical marker for pine wood.

Already after 1 min of charring, only a small amount of dehydroabietic acid derivates and no other resin acids or stilbenes were detected for the pine char (Table 3), indicating a low thermal stability of these conifer biomarkers. The TIC of the P1M char showed a strong relative accumulation of vanillin with $22.7 \%$ (Table 3), confirming that some lignin derivatives survives the charring process (Knicker et al., 2008). The signal of vanillin completely disappears in the chromatogram of the sample after 4 min of charring, indicating a complete demethoxylation of the lignin structures. 
Levoglucosan is detectable in all fresh PyOM, but has the highest contribution in P1M (17.2\% of TIC) (Table 3). The grass-derived PyOM contains a smaller fraction of LG. With prolonged charring time $(4 \mathrm{~min})$ the total amount of levoglucan decreased by $86.1 \%$ and 97.6\% relative to the PyOM of rye grass and pine wood obtained after one minute of charring, respectively. This interferes that severely burnt plant material can be depleted in levoglucan, which is in line with the study of (Kuo et al., 2008) who detect levoglucan only in low temperature char $\left(150-350^{\circ} \mathrm{C}\right)$.

The content of resinic acids in the pine-PyOM incubates showed no clear trend during incubation. Degradation was observed only for the P4M incubate and was indicated by a small recovery of $23 \%$ of the amount identified in the fresh char. Comparably, Dorado et al. (2000) described an elimination of resinic acids by $80 \%$ in the acetone extractives of Scots pine sapwood after treatment of the latter with various white-rot fungi for four weeks. Whiterot fungi can also be responsible for the degradation of resinic acids that survived the charring in the PyOM.

The vanillin residues of the pine chars were efficiently decomposed during the seven weeks incubation period. Only $8 \%$ of the initial amount was recovered for the $\mathrm{P}_{1} \mathrm{M}_{\mathrm{Inc}}$ and the small initial content of P4M was completely degraded (Table 3). This loss is most likely caused by white-rot fungi, which are able to efficiently attack lignin structures (Blanchette, 1991; Hatakka, 1994).

The levoglucan was completely decomposed during incubation of the grass-derived PyOM. The sample P1M lost already $77 \%$ of its levoglucan (Table 3). Although environmental studies examining the fate of LG in soils and sediments are scarce, laboratory experiments confirmed that LG can be fermented and metabolised by yeasts and fungi (Kitamura et al., 1991; Prosen et al., 1993). In line with this observation, Xie et al. (2006) were able to isolate twenty six types of levoglucan-assimilating microorganisms from four types of soils in China. Thus, the use of LG as a tracer for burning in soil has to be seen with care, since its degradation in the post-fire environment may lead to underestimation of charcoal input.

\section{Summary and Conclusion}

Our study clearly confirms that fire-induced thermal breakdown processes affect the quantity and quality of the lipid fraction remaining in the chars. This includes the thermal breakdown of both the $n$-alkanes and FA fraction. In particular the average chain length of $n$-alkanes was reduced and the characteristic odd/even predominance of fresh plant materials was shifted 
towards a balanced odd/even distribution with prolonging charring time. The unsaturated FA fraction was more depleted in relation to the saturated counterparts after charring. Levoglucosan occurred in all PyOM, although the progressive heating resulted in a strong depletion of LG for both plant materials. The pine char shows a relative accumulation of vanillin, confirming that some lignin-type structures survived the charring process. The incubation experiments indicated that decomposition of PyOM in soil further modifies the $n$ alkane and FA fraction by both by degradation but also by in situ biosynthesis most tentatively through fungi. Thus, the survival of the pattern of the thermally altered lipid fraction in fire-affected soils is limited. Comparably, the tracer levoglucan was efficiently decomposed, indicating that at least under optimal environmental conditions the use of this compound as an soil biomarker for vegetation fire events or of char presence has to be taken with cation.

\section{Acknowledgements:}

The European Science Foundation (ESF) within the framework "Natural molecular structures as drivers and tracers of terrestrial C fluxes" (MOLTER) and the International Humic Substances Society (IHSS) are gratefully thanked for enabling the stay of André Hilscher in Seville. Financial support was given by the Spanish Ministerio de Ciencia e Innovación (MICINN) (CGL2009-10557).

\section{References}

Almendros, G., Martín, F. and González-Vila, F.J., 1988. Effects of fire on humic and lipid fractions in a Dystric Xerochrept in Spain. Geoderma, 42: 115-127.

Almendros, G., González-Vila, F.J. and Martín, F., 1990. Fire-induced transformation of soil organic matter from an oak forest. An experimental approach to the effects of fire on humic substances. Soil Science, 149: 158-168.

Amblès, A., Parlanti, E., Jambu, P., Mayoungou, P. and Jacquesy, J.-C., 1994. n-Alkane oxidation in soil. Formation of internal monoalkenes. Geoderma, 64(1-2): 111-124.

Bird, M.I., Veenendaal, E.M., Moyo, C., Lloyd, J. and Frost, P., 1999. Stability of elemental carbon in a savanna soil. Global Biogeochemical Cycles, 13: 923-932. 
Blanchette, R.A., 1991. Delignification by wood-decay fungi. Annual Review of Phytopathology, 29: 381-398.

Breger, I., 1966. Geochemistry of lipids. Journal of the American Oil Chemists' Society, 43(4): 197-202.

Cooney, J.J. and Proby, C.M., 1971. Fatty acid composition of cladosporium-resinae grown on glucose and on hydrocarbons. Journal of Bacteriology, 108: 777-781.

Dinel, H., Schnitzer, M. and Mehuys, G.R., 1990. Soil lipids: Origin, nature, contents, decomposition and effect on soil physical properties. In: J.M. Bollag and G. Stotzky (Editors), Soil Biochemistry. Marcel Dekker, New York, pp. 397-427.

Dorado, J., Claassen, F.W., van Beek, T.A., Lenon, G., Wijnberg, J. and Sierra-Alvarez, R., 2000. Elimination and detoxification of softwood extractives by white-rot fungi. Journal of Biotechnology, 80: 231-240.

Dungait, J.A.J., Docherty, G., Straker, V. and Evershed, R.P., 2010. Seasonal variations in bulk tissue, fatty acid and monosaccharide $\delta^{13} \mathrm{C}$ values of leaves from mesotrophic grassland plant communities under different grazing managements. Phytochemistry, 71(4): 415-428.

Eckmeier, E. and Wiesenberg, G.L.B., 2009. Short-chain n-alkanes (C16-20) in ancient soil are useful molecular markers for prehistoric biomass burning. Journal of Archaeological Science, 36(7): 1590-1596.

Eglinton, G., Gonzalez, A.G., Hamilton, R.J. and Raphael, R.A., 1962. Hydrocarbon constituents of the wax coatings of plant leaves: A taxonomic survey. Phytochemistry, 1(2): 89-102.

Eglinton, G. and Hamilton, R.J., 1967. Leaf epicuticular waxes. Science, 156: 1322-1335.

Elias, V.O., Simoneit, B.R.T., Cordeiro, R.C. and Turcq, B., 2001. Evaluating levoglucosan as an indicator of biomass burning in Carajás, Amazonia: A comparison to the charcoal record. Geochimica et Cosmochimica Acta, 65: 267-272. 
Fengel, D. and Wegener, G., 1984. Wood: Chemistry, Ultrastructure, Reaction. De Gruyter, Berlin.

Foppen, F.H. and Gribanov, O., 1968. Lipids produced by Epicoccum nigrum in submerged culture. Biochemical Journal, 106: 97-100.

Fridland, Y.V., 1982. Some characteristics of soil lipids as a function of ecological conditions. Soviet Soil Science, 14: 80-88.

González-Pérez, J.A., González-Vila, F.J., González-Vázquez, R., Arias, M.E., Rodríguez, J. and Knicker, H., 2008. Use of multiple biogeochemical parameters to monitor the recovery of soils after forest fires. Organic Geochemistry

Advances in Organic Geochemistry 2007 - Proceedings of the 23rd International Meeting on Organic Geochemistry, 39(8): 940-944.

González-Vila, F.J., Tinoco, P., Almendros, G. and Martin, F., 2001. Pyrolysis-GC-MS analysis of the formation and degradation stages of charred residues from lignocellulosic biomass. Journal of Agriculture and Food Chemistry, 49: 1128-1131.

González-Vila, F.J., Polvillo, O., Boski, T., Moura, D. and de Andrés, J.R., 2003. Biomarker patterns in a time-resolved holocene/terminal Pleistocene sedimentary sequence from the Guadiana river estuarine area (SW Portugal/Spain border). Organic Geochemistry, 34(12): 1601-1613.

Hamer, U., Marschner, B., Brodowski, S. and Amelung, W., 2004. Interactive priming of black carbon and glucose mineralisation. Organic Geochemistry, 35: 823-830.

Hatakka, A., 1994. Lignin-modifying enzymes from selected white-rot fungi: production and role from in lignin degradation. FEMS Microbiology Reviews, 13(2-3): 125-135.

Hilscher, A., Heister, K., Siewert, C. and Knicker, H., 2009. Mineralisation and structural changes during the initial phase of microbial degradation of pyrogenic plant residues in soil. Organic Geochemistry, 40(3): 332-342. 
Jaffé, R., Elismé, T. and Cabrera, A.C., 1996. Organic geochemistry of seasonally flooded rain forest soils: molecular composition and early diagenesis of lipid components. Organic Geochemistry, 25(1-2): 9-17.

Jansen, B., Nierop, K.G.J., Hageman, J.A., Cleef, A.M. and Verstraten, J.M., 2006. The straight-chain lipid biomarker composition of plant species responsible for the dominant biomass production along two altitudinal transects in the Ecuadorian Andes. Organic Geochemistry, 37(11): 1514-1536.

Jones, J.G., 1969. Studies on lipids of soil micro-organisms with particular reference to hydrocarbons. Journal of General Microbiology, 59(2): 145-152.

Kitamura, Y., Abe, Y. and Yasui, T., 1991. Metabolism of levoglucosan (1,6-anhydro-beta-dglucopyranose) in microorganisms. Agricultural and Biological Chemistry, 55: 515521.

Knicker, H., Hilscher, A., González-Vila, F.J. and Almendros, G., 2008. A new conceptual model for the structural properties of char produced during vegetation fires. Organic Geochemistry, 39(8): 935-939.

Knicker, H., González Vila, F.J. and González Vázquez, R., 2012. Biodegradability of organic matter in fire-affected mineral soils of Southern Spain. Soil Biology and Biochemistry, submitted.

Kuhn, T.K., Krull, E.S., Bowater, A., Grice, K. and Gleixner, G., 2010. The occurrence of short chain n-alkanes with an even over odd predominance in higher plants and soils. Organic Geochemistry, 41(2): 88-95.

Kuo, L.-J., Herbert, B.E. and Louchouarn, P., 2008. Can levoglucosan be used to characterize and quantify char/charcoal black carbon in environmental media? Organic Geochemistry, 39(10): 1466-1478. 
Lakshman, C.M. and Hoelsche, H.E., 1970. Production of levoglucosan by pyrolysis of carbohydrates - pyrolysis in hot inert stream. Industrial \& Engineering Chemistry Product Research and Development, 9: 57-59.

Maffei, M., 1996. Chemotaxonomic significance of leaf wax n-alkanes in the Umbelliferae, Cruciferae and Leguminosae (Subf. Papilionoideae). Biochemical Systematics and Ecology, 24(6): 531-545.

Marseille, F., Disnar, J.R., Guillet, B. and Noack, Y., 1999. n-Alkanes and free fatty acids in humus and A1 horizons of soils under beech, spruce and grass in the Massif-Central (Mont-Lozère), France. European Journal of Soil Science, 50(3): 433-441.

Merdinger, E. and Devine, E.M., 1965. Lipids of Debaryomyces hansenii. Journal of Bacteriology, 89: 1488-1493.

Merdinger, E., Kohn, P. and McClain, R.C., 1968. Composition of lipids in extracts of Pullularia pullulans. Canadian Journal of Microbiology, 14: 1021-1027.

Nguyen Tu, T.T., Derenne, S., Largeau, C., Mariotti, A. and Bocherens, H., 2001. Evolution of the chemical composition of Ginkgo biloba external and internal leaf lipids through senescence and litter formation. Organic Geochemistry, 32(1): 45-55.

Otto, A., Gondokusumo, R. and Simpson, M.J., 2006. Characterization and qualification of biomarkers from biomass burning at a recent wildfire site in Northern Alberta, Canada. Applied Geochemistry, 21: 166-183.

Prosen, E.M., Radlein, D., Piskorz, J., Scott, D.S. and Legge, R.L., 1993. Microbial utilization of levoglucosan in wood pyrolysate as a carbon and energy-source. Biotechnology and Bioengineering, 42: 538-541.

Rambo, G.W. and Bean, G.A., 1969. Fatty acids of mycelia and conidia of Fusarium oxysporum and Fusarium roseum. Canadian Journal of Microbiology, 15: 96-968.

Sharma, R.K., Wooten, J.B., Baliga, V.L., Lin, X., Chan, W.G. and Hajaligol, M.R., 2004. Characterization of chars from pyrolysis of lignin. Fuel, 83: 1469-1482. 
Simoneit, B.R.T., Schauer, J.J., Nolte, C.G., Oros, D.R., Elias, V.O., Fraser, M.P., Rogge, W.F. and Cass, G.R., 1999. Levoglucosan, a tracer for cellulose in biomass burning and atmospheric particles. Atmospheric Environment, 33(2): 173-182.

Simoneit, B.R.T. and Elias, V.O., 2001. Detecting organic tracers from biomass burning in the atmosphere. Marine Pollution Bulletin, 42: 805-810.

Stevenson, F.J., 1994. Humus Chemistry - Genesis, Composition, Reactions. John Wiley \& Sons, Inc., New York, 496 pp.

Tinoco, P., Almendros, G., Sanz, J., González-Vázquez, R. and González-Vila, F.J., 2006. Molecular descriptors of the effect of fire on soils under pine forest in two continental Mediterranean soils. Organic Geochemistry, 37(12): 1995-2018.

Valentin, L., Kluczek-Turpeinen, B., Willfor, S., Hemming, J., Hatakka, A., Steffen, K. and Tuomela, M., 2010. Scots pine (Pinus sylvestris) bark composition and degradation by fungi: Potential substrate for bioremediation. Bioresource Technology, 101: 22032209.

Wiesenberg, G.L.B., Schwarzbauer, J., Schmidt, M.W.I. and Schwark, L., 2004. Source and turnover of organic matter in agricultural soils derived from n-alkane/n-carboxylic acid compositions and C-isotope signatures. Organic Geochemistry, 35(11-12): 13711393.

Wiesenberg, G.L.B., Lehndorff, E. and Schwark, L., 2009. Thermal degradation of rye and maize straw: Lipid pattern changes as a function of temperature. Organic Geochemistry, 40(2): 167-174.

Willför, S., Hemming, J., Reunanen, M. and Holmbom, B., 2003. Phenolic and lipophilic extractives in scots pine knots and stemwood, Holzforschung, pp. 359.

WRB, I.W.G., 2006. World Reference Base for Soil Resources. World Soil Resources Reports 103. FAO, Rome. 
Xie, H., Zhuang, X., Bai, Z., Qi, H. and Zhang, H., 2006. Isolation of levoglucosanassimilating microorganisms from soil and an investigation of their levoglucosan kinases. World Journal of Microbiology and Biotechnology, 22(9): 887-892.

Yokelson, R.J., Susott, R., Ward, D.E., Reardon, J. and Griffith, D.W.T., 1997. Emissions from smoldering combustion of biomass measured by open-path Fourier transform infrared spectroscopy. Journal of Geophysical Research 102: 18865-18877. 
Table 1. Abundance and molecular ratios for $n$-alkanes and fatty acids of the fresh and charred rye grass $(\mathrm{Gr})$ and pine wood (P).

\begin{tabular}{|c|c|c|c|c|c|c|c|c|c|c|c|c|c|}
\hline \multirow[b]{2}{*}{ Sample } & \multirow{2}{*}{$\begin{array}{c}\text { total } \\
\text { extract } \\
\mathrm{mg} \mathrm{g}^{-1}\end{array}$} & \multicolumn{5}{|c|}{$n$-alkanes } & \multicolumn{4}{|c|}{ saturated FA } & \multicolumn{3}{|c|}{ unsaturated FA } \\
\hline & & $\begin{array}{l}\text { yield }^{\mathrm{a}} \\
\mu \mathrm{g} \mathrm{g}^{-1}\end{array}$ & $\mathrm{ACL}^{\mathrm{b}}$ & $\mathrm{CPI}^{\mathrm{c}}$ & $\mathrm{CPI}_{\text {long }}{ }^{\mathrm{d}}$ & $\mathrm{R}_{\mathrm{s} / 1}^{\mathrm{e}}$ & $\begin{array}{l}\text { yield }^{\mathrm{a}} \\
\mu \mathrm{g} \mathrm{g}^{-1}\end{array}$ & $\mathrm{ACL}^{\mathrm{b}}$ & $\mathrm{CPI}^{\mathrm{f}}$ & $\mathrm{R}_{\mathrm{FAs} / 1^{\mathrm{g}}}$ & $\begin{array}{l}\text { yield }^{\mathrm{a}} \\
\mu \mathrm{g} \mathrm{g}^{-1}\end{array}$ & $\begin{array}{c}\text { portion }^{\mathrm{h}} \\
\% \\
\end{array}$ & $\mathrm{C}_{18: 1-3 / 3} / \mathrm{C}_{18: 0}$ \\
\hline GrOM & 67 & 55 & 27.7 & 3.4 & 5.5 & 0.5 & 4307 & 16.7 & 24.5 & 10.7 & 5622 & 56.6 & 19.4 \\
\hline Gr1M & 41 & 199 & 24.2 & 1.2 & 0.9 & 2.7 & 3540 & 16.4 & 10.2 & 12.8 & 1525 & 30.1 & 5.5 \\
\hline Gr4M & 12 & 142 & 23.5 & 1.0 & 1.1 & 4.1 & 1127 & 16.4 & 8.6 & 14.3 & 98 & 8.0 & 0.6 \\
\hline POM & 62 & 19 & 21.8 & 1.6 & - & 2.8 & 191 & 17.2 & 40.6 & 4.3 & 448 & 70.2 & 28.2 \\
\hline P1M & 18 & 39 & 21.6 & 1.1 & 1.2 & 6.5 & 119 & 15.9 & 6.9 & 8.5 & 62 & 34.4 & 7.1 \\
\hline P4M & 3 & 21 & 21.3 & 0.9 & 0.8 & 7.4 & 145 & 16.9 & 14.9 & 17.5 & 24 & 14.4 & 0.5 \\
\hline
\end{tabular}

${ }^{\mathrm{a}}$ Total abundance $=\sum \mathrm{z}_{\mathrm{n}}$, with $\mathrm{z}_{\mathrm{n}}$ as relative amount of $n$-alkane or fatty acid with $\mathrm{n}$ carbons.

${ }^{\mathrm{b}}$ Average chain length $\left.=\sum \mathrm{z}_{\mathrm{n}} \times \mathrm{n}\right) / \sum \mathrm{z}_{\mathrm{n}}$ ), with $\mathrm{z}_{\mathrm{n}}$ as relative amount of $n$-alkane or fatty acid with $\mathrm{n}$ carbons.

${ }^{\mathrm{c}}$ Carbon preference index of $n$-alkanes $=\left[\left(\sum \mathrm{C}_{17-31 \text { odd }} / \sum \mathrm{C}_{16-30 \text { even }}\right)+\left(\sum \mathrm{C}_{17-31 \text { odd }} / \sum \mathrm{C}_{18-32 \text { even }}\right)\right] \times 0.5$.

${ }^{\mathrm{d}}$ Carbon preference index of long chain $n$-alkanes $=\left[\left(\sum \mathrm{C}_{25-31 \text { odd }} / \sum \mathrm{C}_{24-30 \mathrm{even}}\right)+\left(\sum \mathrm{C}_{25-31 \text { odd }} / \sum \mathrm{C}_{26-32 \text { even }}\right)\right] \times 0.5$.

${ }^{\mathrm{e}}$ Ratio between short and long chain $n$-alkanes $\mathrm{R}_{\mathrm{s} / 1}=\sum \mathrm{C}_{15-26} / \sum \mathrm{C}_{26-35}$.

${ }^{\mathrm{f}}$ Carbon preference index of fatty acids $=\left[\left(\sum \mathrm{C}_{10-28 \text { even }} / \sum \mathrm{C}_{9-27 \text { odd }}\right)+\left(\sum \mathrm{C}_{10-28 \mathrm{even}} / \sum \mathrm{C}_{11-29 \mathrm{odd}}\right)\right] \times 0.5$.

${ }^{\mathrm{g}}$ Ratio between short and long chain fatty acid $\mathrm{R}_{\mathrm{FA} / \mathrm{l}}=\sum \mathrm{C}_{10-20} / \sum \mathrm{C}_{21-28}$.

$\mathrm{h}$ Percentage of unsaturated fatty acids to total fatty acid amount. 
Table 2. Abundance and molecular ratios for $n$-alkanes and fatty acids of the incubated PyOM from rye grass (Gr) and pine wood (P).

\begin{tabular}{|c|c|c|c|c|c|c|c|c|c|c|c|c|c|c|c|c|}
\hline \multirow[b]{2}{*}{ Sample } & \multicolumn{2}{|c|}{ total extract } & \multicolumn{6}{|c|}{ n-alkanes } & \multicolumn{5}{|c|}{ saturated FA } & \multicolumn{3}{|c|}{ unsaturated FA } \\
\hline & $\mathrm{mg} \mathrm{g}^{-1}$ & $\mathrm{RC}(\%)$ & $\begin{array}{l}\text { yield }^{\mathrm{a}} \\
\mu \mathrm{g} \mathrm{g}^{-1}\end{array}$ & $\mathrm{RC}(\%)^{\mathrm{b}}$ & $\mathrm{ACL}^{\mathrm{c}}$ & $\mathrm{CPI}^{\mathrm{d}}$ & $\mathrm{CPI}_{\text {long }}{ }^{\mathrm{e}}$ & $\mathrm{R}_{\mathrm{s} / 1}^{\mathrm{f}}$ & $\begin{array}{l}\text { yield }^{\mathrm{a}} \\
\mu \mathrm{g} \mathrm{g}^{-1}\end{array}$ & $\mathrm{RC}(\%)^{\mathrm{b}}$ & $\mathrm{ACL}^{\mathrm{c}}$ & $\mathrm{CPI}^{\mathrm{g}}$ & $\mathrm{R}_{\mathrm{FA} \mathrm{s} / 1}^{\mathrm{h}}$ & $\begin{array}{l}\text { yield }^{\mathrm{a}} \\
\mu \mathrm{g} \mathrm{g}^{-1}\end{array}$ & $\begin{array}{c}\text { portion }^{i} \\
(\%)\end{array}$ & $\begin{array}{l}\mathrm{RC} \\
(\%)^{\mathrm{b}}\end{array}$ \\
\hline $\mathrm{Gr}_{1} \mathrm{M}_{\mathrm{Inc}}$ & 30 & 44 & 121 & 61 & 22.6 & 1.0 & 1.3 & 9.9 & 2540 & 72 & 16.9 & 8.8 & 7.2 & 145 & 5 & 71 \\
\hline $\mathrm{Gr}_{4} \mathrm{M}_{\text {Inc }}$ & 9 & 74 & 121 & 85 & 22.7 & 1.1 & 1.1 & 6.6 & 746 & 66 & 16.5 & 6.4 & 7.7 & 49 & 6 & 50 \\
\hline $\mathrm{P} 1 \mathrm{M}_{\text {Inc }}$ & 10 & 55 & 53 & 295 & 22.7 & 0.9 & 1.1 & 2.2 & 319 & 269 & 16.5 & 6.3 & 7.6 & 140 & 30 & 225 \\
\hline $\mathrm{P} 4 \mathrm{M}_{\text {Inc }}$ & 5 & 147 & 63 & 253 & 22.9 & 1.0 & 1.6 & 2.1 & 672 & 464 & 17.2 & 11.4 & 7.8 & 9 & 1 & 37 \\
\hline
\end{tabular}

${ }^{\mathrm{a}}$ Total abundance $=\sum \mathrm{z}_{\mathrm{n}}$, with $\mathrm{z}_{\mathrm{n}}$ as relative amount of $n$-alkane or fatty acid with $\mathrm{n}$ carbons.

${ }^{\mathrm{b}}$ Relative recovery of total $n$-alkane or fatty acid amount for the incubates.

$c$ Average chain length $\left.\left.=\sum \mathrm{z}_{\mathrm{n}} \times \mathrm{n}\right) / \sum \mathrm{z}_{\mathrm{n}}\right)$, with $\mathrm{z}_{\mathrm{n}}$ as relative amount of $n$-alkane or fatty acid with $\mathrm{n}$ carbons.

${ }^{\mathrm{d}}$ Carbon preference index of $n$-alkanes $=\left[\left(\sum \mathrm{C}_{17-31 \text { odd }} / \sum \mathrm{C}_{16-30 \mathrm{even}}\right)+\left(\sum \mathrm{C}_{17-31 \text { odd }} / \sum \mathrm{C}_{18-32 \text { even }}\right)\right] \times 0.5$.

${ }^{\mathrm{e}}$ Carbon preference index of long chain $n$-alkanes $=\left[\left(\sum \mathrm{C}_{25-31 \text { odd }} / \sum \mathrm{C}_{24-30 \mathrm{even}}\right)+\left(\sum \mathrm{C}_{25-31 \text { odd }} / \sum \mathrm{C}_{26-32 \mathrm{even}}\right)\right] \times 0.5$.

${ }^{\mathrm{f}}$ Ratio between short and long chain $n$-alkanes $\mathrm{R}_{\mathrm{s} / 1}=\sum \mathrm{C}_{15-26} / \sum \mathrm{C}_{25-35}$.

${ }^{\mathrm{g}}$ Carbon preference index of fatty acids $=\left[\left(\sum \mathrm{C}_{10-28 \mathrm{even}} / \sum \mathrm{C}_{9-27 \text { odd }}\right)+\left(\sum \mathrm{C}_{10-28 \mathrm{even}} / \sum \mathrm{C}_{11-29 \mathrm{odd}}\right)\right] \times 0.5$.

${ }^{\mathrm{h}}$ Ratio between short and long chain fatty acid $\mathrm{R}_{\mathrm{FA} \mathrm{s} / \mathrm{l}}=\sum \mathrm{C}_{10-20} / \sum \mathrm{C}_{21-28}$.

${ }^{\mathrm{i}}$ Percentage of unsaturated fatty acids on total fatty acid amount. 
Table 3. Specific biomarker abundances according to total ion current (TIC) of fresh and charred rye grass $(\mathrm{Gr})$ and pine wood $(\mathrm{P})$ and respective recovery $(\mathrm{RC})$ from the incubated PyOM

\begin{tabular}{|c|c|c|c|c|c|c|}
\hline \multirow[t]{3}{*}{ Sample } & \multicolumn{2}{|c|}{ Vanillin } & \multicolumn{2}{|c|}{ Resinic acids $^{\mathrm{a}}$} & \multicolumn{2}{|c|}{ Levoglucosan $^{b}$} \\
\hline & TIC & $\mathrm{RC}$ & TIC & $\mathrm{RC}$ & TIC & $\mathrm{RC}$ \\
\hline & $(\%)^{\mathrm{c}}$ & $(\%)^{\mathrm{d}}$ & $(\%)^{\mathrm{c}}$ & $(\%)^{\mathrm{d}}$ & $(\%)^{\mathrm{c}}$ & $(\%)^{\mathrm{d}}$ \\
\hline GrOM & - & - & - & - & - & - \\
\hline Gr1M & - & - & - & - & 3.6 & 0 \\
\hline Gr4M & - & - & - & - & 1.7 & 0 \\
\hline $\mathrm{P} 0 \mathrm{M}$ & 2.2 & - & 18.6 & - & - & - \\
\hline $\mathrm{P} 1 \mathrm{M}$ & 22.7 & 8 & 1.0 & 149 & 17.2 & 23 \\
\hline P4M & 0.3 & 0 & 3.5 & 23 & 2.2 & 85 \\
\hline
\end{tabular}

${ }^{\text {a }}$ Conifer biomarker (sum of abietic acid, dehydroabietic acid, 7-oxodehydroabietic acid and primeric acid)

${ }^{\mathrm{b}}$ Indicator for biomass burning

${ }^{c}$ Percentage of the area of the total ion current (TIC) in the chromatogram of the fresh PyOM ${ }^{\mathrm{d}}$ Total recovery of biomarkers for the incubated PyOM 


\section{Figure caption}

Fig. 1. Abundances of $n$-alkanes in the extracts from rye grass $(\mathrm{Gr})$ and pine wood $(\mathrm{P})$ and the respective fresh and incubated PyOM.

Fig.2. Abundances of fatty acids in the extract isolated with dichormethane-methanol from rye grass $(\mathrm{Gr})$ and pine wood $(\mathrm{P})$ and the respective fresh and incubated PyOM. 
Figure 1
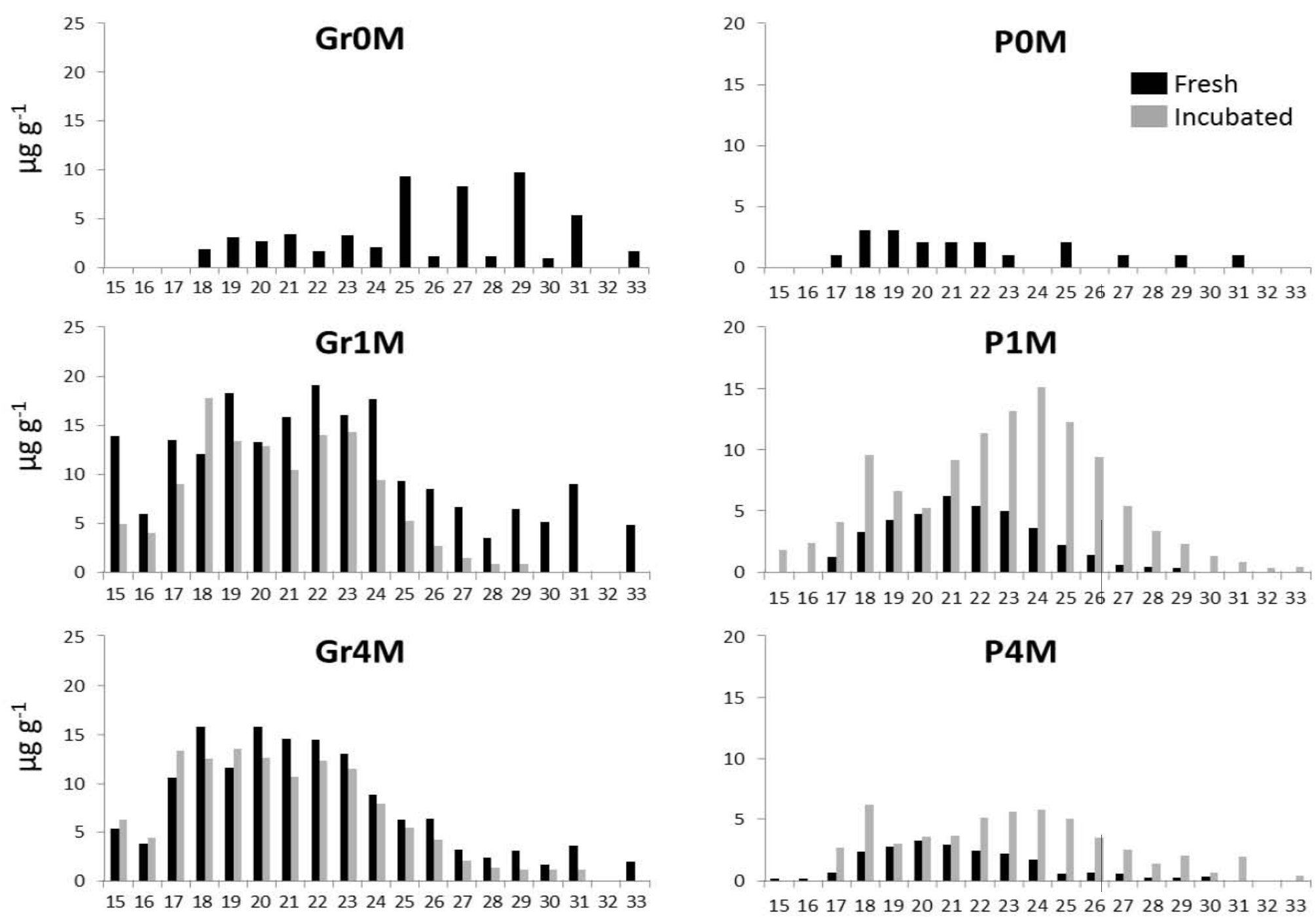


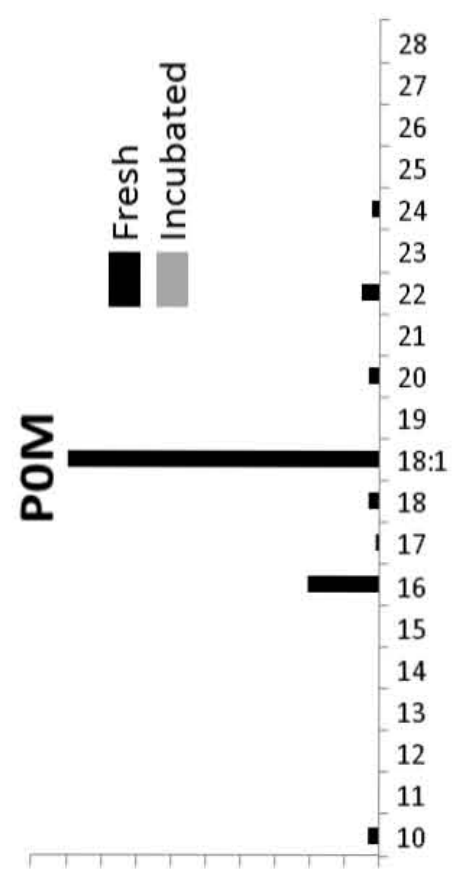

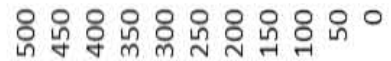

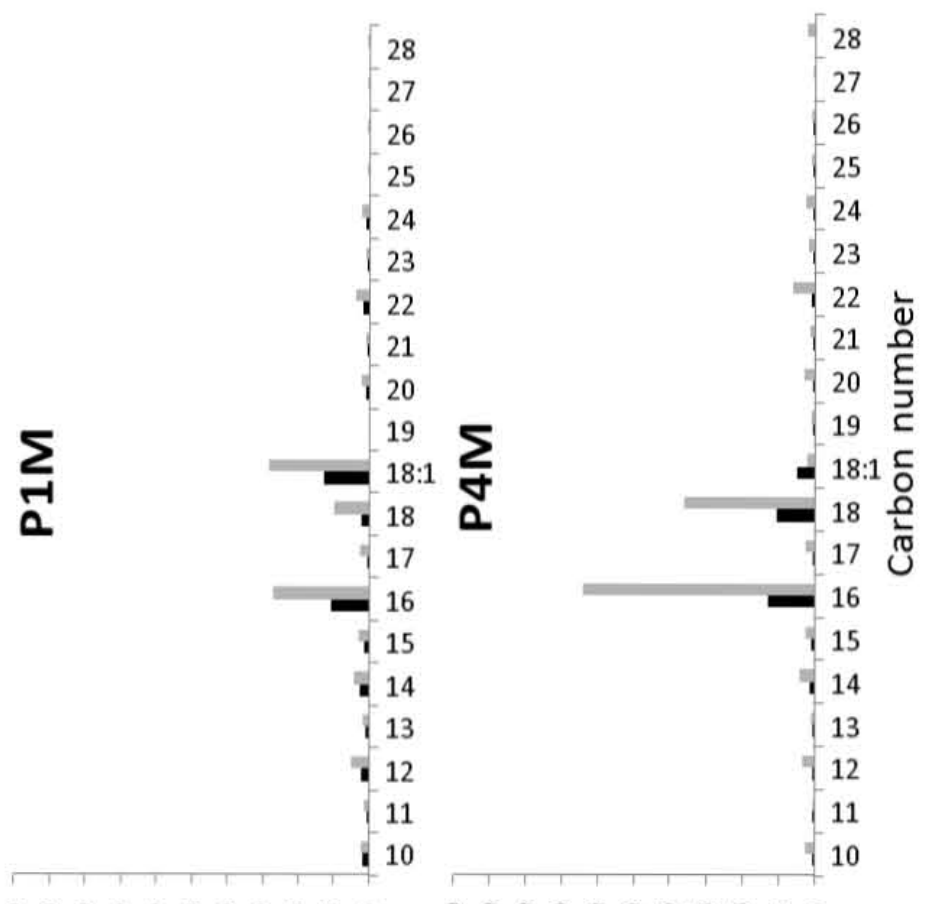

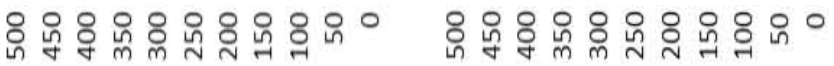

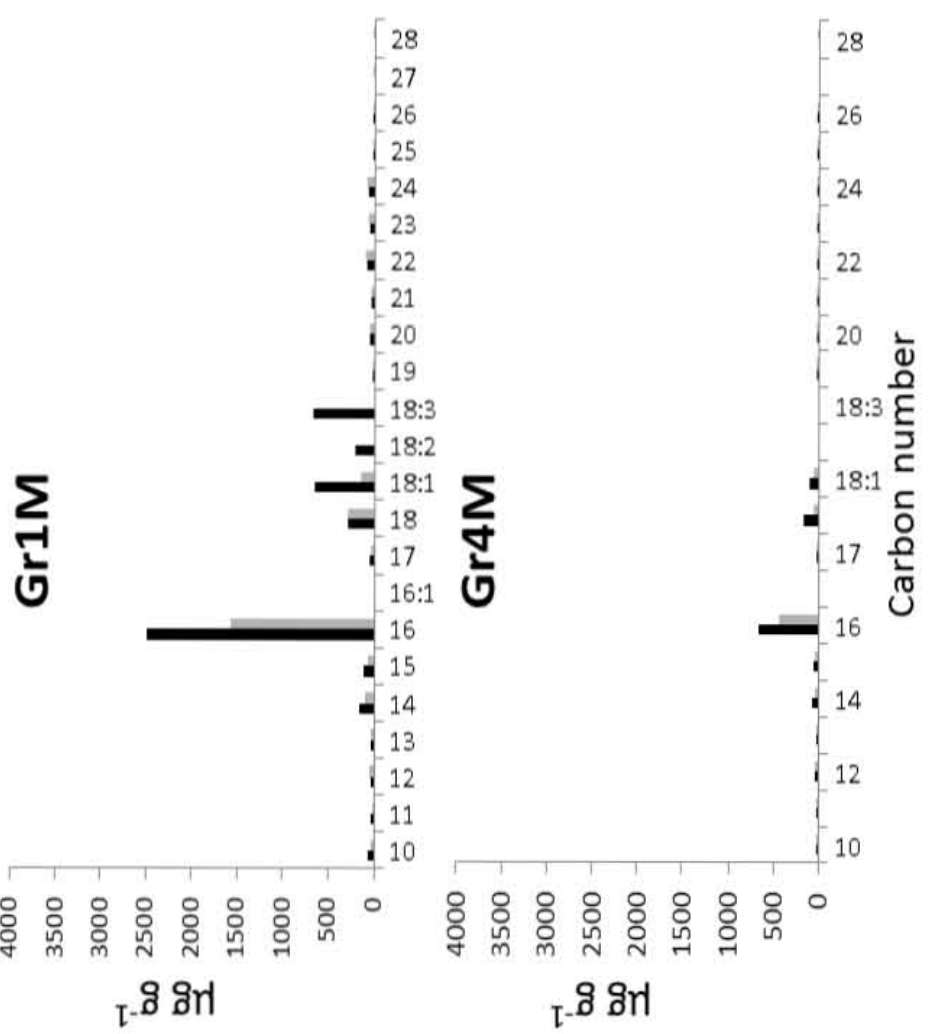

